\title{
Vestibular Rehabilitation for Dizziness and Imbalance Following Concussion: A Critically Appraised Topic
}

\author{
lan McGinnis, BS, LAT, ATC, Justin Cobb, BS, LAT, ATC, Ryan Tierney, PhD, LAT, ATC, \\ and Anne Russ, PhD, LAT, ATC \\ Temple University
}

\begin{abstract}
Clinical Question: What is the efficacy of vestibular rehabilitation for treating imbalance and self-reported dizziness in patients experiencing prolonged symptoms of concussion? Clinical Bottom Line: There is consistent, but low-level, evidence supporting that vestibular rehabilitation can have a positive effect on self-reported dizziness (dizziness severity, Dizziness Handicap Inventory [DHI], Activities-Specific Balance Confidence Scale [ABC]) and objective balance (Sensory Organization Test [SOT], Balance Error Scoring System [BESS]) in patients with prolonged symptoms following concussion. Vestibular rehabilitation is not for every concussed patient. Several, though few, patients did not improve or became worse with the implementation of vestibular rehabilitation. Many of the vestibular rehabilitation exercises utilized in these studies are easily accessible to athletic trainers and, with informed decision making and proper oversight, could be implemented in the athletic training room.
\end{abstract}

Keywords: evidence-based, mTBI, recovery

\section{Introduction/Clinical Scenario}

Dizziness and imbalance are two of the most commonly-reported symptoms in the early stages of concussion. Anywhere from 23$81 \%$ of patients report dizziness in the days following injury. ${ }^{1-3} \mathrm{An}$ initial presentation of dizziness can be a predictor of prolonged recovery from concussion, both in athletic and general populations. ${ }^{4-6}$ The vestibular system's regulation of balance, spatial orientation, and gaze stability plays a key role in athletic tasks and many activities of daily living. Disruption of the vestibular system can exacerbate other symptoms of concussion and prolong recovery further. Initial clinical findings of dizziness and imbalance through subjective means or objective testing require further investigation and initiation of appropriate management strategies. ${ }^{4}$ Assessment of vestibular/ocular function and sensory integration can include smooth pursuits, saccadic eye movements, near-point convergence testing, vestibulo-ocular reflex testing, visual motion sensitivity testing, the Balance Error Scoring System (BESS) test, and the Sensory Organization Test (SOT).$^{7}$

Most individuals who experience a sport-related concussion will clinically recover within 1 month. ${ }^{8}$ For dizziness and imbalance caused by concussion that do not resolve spontaneously within this time frame, vestibular rehabilitation is thought to bring about symptom resolution. The cause of these symptoms must be determined as either central or peripheral. Central causes include diffuse mild brain injury while peripheral causes involve damage to specific vestibular structures including the semi-circular canals and macular organs. These two sources of dizziness and imbalance require distinctly different courses of treatment. ${ }^{4}$ Those with central causes will most likely benefit more from vestibular rehabilitation while those with peripheral causes require further investigation and will likely benefit from a combination of specific

McGinnis, Cobb, Tierney, and Russ are with the Department of Kinesiology, Temple University, Philadelphia, PA. Russ (anne.russ@temple.edu) is corresponding author. interventions like a canalith repositioning maneuver and vestibular rehabilitation.

Therapeutic exercise prescription for vestibular rehabilitation is individualized based upon the patient's dizziness profile and functional challenges. ${ }^{1,3,9}$ Common exercise types and their modifiers are described by Alsalaheen et al. ${ }^{3}$ The development of advanced technology has enabled some clinicians to create virtual-reality environments to immerse their patients in situations that are congruent to their athletic or work setting. ${ }^{9}$ Vestibular ocular exercises as a whole and all of their modifications challenge the vestibulo-ocular, vestibulospinal, and vestibulocollic reflexes. ${ }^{4}$ Outpatient sessions are typically supplemented by home exercise programs that are performed daily. Due to a lack of consistency in exercise prescription and administration, it is difficult to make meaningful assertions about the effect of vestibular rehabilitation on resolving dizziness and imbalance.

\section{Focused Clinical Question}

What is the efficacy of vestibular rehabilitation for treating imbalance and self-reported dizziness in patients experiencing prolonged symptoms of concussion?

\section{Search Strategy}

A search of PubMed and SPORTDiscus was conducted in February of 2017 using the following PIO (patient group, intervention, outcome) setup as a means to generate a Boolean phrase. Boolean phrase: vestib* AND rehab* AND (concussion OR "mild traumatic brain injury" OR mTBI OR traumatic brain injury" or TBI) AND dizziness AND balance.

- Patient group: Concussed patients experiencing prolonged dizziness and imbalance

- Intervention: Vestibular rehabilitation 
Table 1 Description of Outcome Measures

\begin{tabular}{lll}
\hline Outcome Measure & Scoring & Assessing \\
\hline Dizziness severity & $\begin{array}{l}\text { Patients asked to rate their perceived dizziness on a 100-point scale; } \\
\text { range }=0-100 \text { (best-worst) }\end{array}$ & Self-reported dizziness \\
Activities-specific Balance & 16 items rated from 0-100; average is taken for the total score; & Self-reported impairment caused \\
Confidence Scale (ABC) & range $=0-100$ (worst-best) & by dizziness \\
Dizziness Handicap & 25 items scored on three response levels (yes =4, sometimes =2, & Self-reported impairment caused \\
Inventory (DHI) & no=0); range=0-100 (best-worst) & by dizziness \\
Sensory Organization Test & Six conditions scored with the average taken as the composite; & Postural stability, postural sway, \\
(SOT) composite score & range $=0-100$ (worst-best) & sensory organization \\
Balance Error Scoring & Six items with a maximal score of 10 per item; range =0-60 (best- & Postural stability and sensory \\
System (BESS) & worst) & integration \\
\hline
\end{tabular}

- Outcome: Subjective and objective measures of dizziness and balance (Table 1)

Inclusion criteria were:

- Studies that used pre- and posttreatment measures

- Studies that used vestibular rehabilitation as therapy

- Outcome measures that were representative of dizziness and balance

- Studies performed within the past 10 years

- Studies published in English

Exclusion criteria were:

- Studies that used aerobic exercise as therapy

- Studies that used cervical rehabilitation as therapy

\section{Evidence Quality Assessment}

Internal and external validity of the selected studies were assessed using the STROBE checklist for cohort studies ${ }^{1,10}$ and the Center for Evidence Based Management (CEBM) critical appraisal of a case study ${ }^{9}$ forms. For each selected study, two researchers independently scored the forms and the averages were used for strength of recommendation.

\section{Results of Search}

\section{Summary of Search, Evidence Appraised, and Key Findings}

In total, our search yielded 109 records (72 from PubMed, 37 from SPORTDiscus). A summary of search results can be seen in Figure 1. Each article included utilized a test retest ${ }^{1,10}$ cohort or case study design. ${ }^{9}$ The articles included in Table 2 met all inclusion criteria and were selected for inclusion in this CAT. Most, but not all, patients improved in every outcome measure of interest-dizziness severity, Dizziness Handicap Inventory (DHI), Activities-Specific Balance Confidence (ABC) scale, SOT, and the BESS test-after completing vestibular rehabilitation.

\section{Results of Evidence Assessment}

Two ${ }^{1,10}$ of the studies were assessed using the STROBE checklist. The Alsalaheen et al. ${ }^{10}$ study received a score of 20/22 and the Kleffelgaard et al. ${ }^{1}$ study received a score of $16.5 / 22$. The third study $^{9}$ was assessed using the CEBM critical appraisal of a case study form and scored an 8/10.

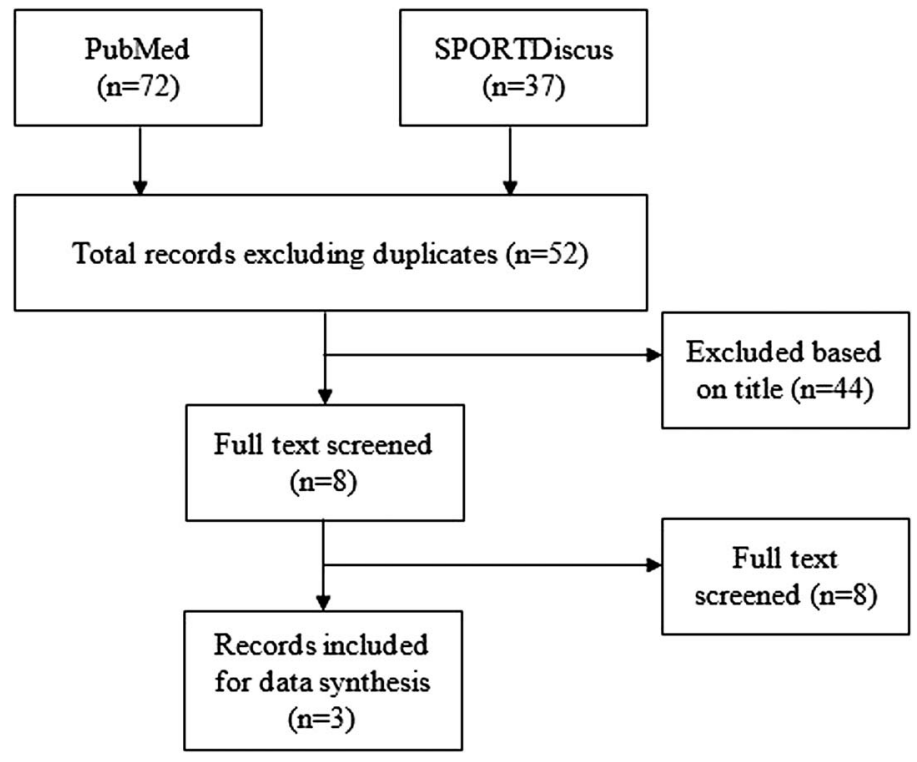

Figure 1 - Summary of search results.

\section{Clinical Bottom Line}

There is consistent, but low-level, evidence supporting that vestibular rehabilitation can have a positive effect on self-reported dizziness (dizziness severity, DHI, ABC) and objective balance (SOT, BESS) on patients with prolonged symptoms following concussion. However, vestibular rehabilitation is not for every concussed patient. Several, though few, patients did not improve or became worse with the implementation of vestibular rehabilitation. Lack of improvement in certain patients may be attributable to cervicogenic symptoms or benign paroxysmal positional vertigo (BPPV) that were not addressed in rehabilitation. Many of the vestibular rehabilitation exercises utilized in these studies are easily accessible to athletic trainers and, with informed decision making and proper oversight, could be implemented in the athletic training room.

\section{Strength of Recommendation}

Results from the involved studies consistently indicate the utility of vestibular rehabilitation. However, the relatively low-level quality of the studies-retrospective cohort, ${ }^{10}$ case series, ${ }^{1}$ and case study ${ }^{9}$ - limit the strength of recommendation. We thereby assign a Strength of Recommendation Taxonomy rating of B. 
Table 2 Characteristics of Included Studies

\begin{tabular}{|c|c|c|c|}
\hline \multirow[b]{2}{*}{ Characteristics } & \multicolumn{3}{|c|}{ Study } \\
\hline & Alsalaheen et al. ${ }^{10}$ & Kleffelgaard et al. ${ }^{1}$ & Gottshall \& Sessoms ${ }^{9}$ \\
\hline Study title & $\begin{array}{l}\text { Vestibular rehabilitation for dizziness } \\
\text { and balance disorders after concussion }\end{array}$ & $\begin{array}{l}\text { Vestibular rehabilitation after traumatic } \\
\text { brain injury: case series }\end{array}$ & $\begin{array}{l}\text { Improvements in dizziness and imbal- } \\
\text { ance results from using a multi-disci- } \\
\text { plinary and multi-sensory approach to } \\
\text { vestibular physical therapy - a case study }\end{array}$ \\
\hline Study participants & $\begin{array}{l}114 \text { patients: } \\
\text { Adults = } 25 \text { women, } 22 \text { men; } \\
\text { mean age } 41 \text { (range }=19-73 \text { ) } \\
\text { Children }=45 \text { girls, } 22 \text { boys; } \\
\text { mean age } 16 \text { (range }=8-18) \\
\text { Median time from injury to } \\
\text { referral = } 61 \text { days (range }=6-2,566)\end{array}$ & $\begin{array}{l}4 \text { patients: } \\
2 \text { men, } 2 \text { women } \\
\text { Mean age }=36 \\
\text { Mean time from injury to initial } \\
\text { encounter }=16.75 \text { months }\end{array}$ & $\begin{array}{l}1 \text { patient: } \\
\text { Male active duty service member } \\
\text { Age }=41 \\
\text { Began physical therapy } 22 \text { days } \\
\text { postinjury }\end{array}$ \\
\hline $\begin{array}{l}\text { Inclusion/ exclusion } \\
\text { criteria }\end{array}$ & $\begin{array}{l}\text { Patients experiencing prolonged } \\
\text { dizziness symptoms referred to a } \\
\text { tertiary balance center for vestibular } \\
\text { rehabilitation following diagnosis } \\
\text { of a concussion }\end{array}$ & $\begin{array}{l}\text { Inclusion: TBI aged between } 16 \text { and } \\
60 \text { years; dizziness reported on } \\
\text { Rivermead Postconcussion Symptoms } \\
\text { Questionnaire; positive Romberg test } \\
\text { Exclusion: Severe psychological } \\
\text { disease; language problems; cognitive } \\
\text { dysfunction; fractures/other } \\
\text { comorbidities affecting mobility }\end{array}$ & N/A \\
\hline Outcome measures & $\begin{array}{l}\text { Collected: Dizziness severity scale, } \\
\text { range }=0-100 \text { (best-worst); ABC Scale, } \\
\text { range }=0-100 \text { (worst-best); DHI, } \\
\text { range }=0-100 \text { (best-worst); SOT, } \\
\text { range } 0-100 \text { (worst-best) } \\
\text { Measured: Pretreatment, posttreatment }\end{array}$ & $\begin{array}{l}\text { Collected: DHI, range }=0-100 \text { (best- } \\
\text { worst); BESS, range }=0-60 \text { (best-worst) } \\
\text { Measured: Pretreatment, posttreatment }\end{array}$ & $\begin{array}{l}\text { Collected: DHI, range }=0-100 \\
\text { (best-worst); ABC Scale, range }=0-100 \\
\text { (worst-best); SOT, range 0-100 } \\
\text { (worst-best) } \\
\text { Measured: Pretreatment, posttreatment }\end{array}$ \\
\hline Results & $\begin{array}{l}\text { Dizziness severity }(\mathrm{n}=64) \\
\text { Pretreatment mean }=21 \\
(95 \% \mathrm{CI}=15.5,26.5) \\
\text { Posttreatment mean }=12 \\
(95 \% \mathrm{CI}=7.5,16.5) \\
\text { Effect size }=0.45 \\
\text { ABC }(\mathrm{n}=68) \\
\text { Pretreatment mean }=64 \\
(95 \% \mathrm{CI}=57.4,70.5) \\
\text { Posttreatment mean }=84 \\
(95 \% \mathrm{CI}=79.9,88.1) \\
\text { Effect size }=0.89 \\
\text { DHI }(\mathrm{n}=69) \\
\text { Pretreatment mean }=49 \\
(95 \% \mathrm{CI}=43.9,54) \\
\text { Posttreatment mean }=30 \\
(95 \% \mathrm{CI}=24.7,35.3) \\
\text { Effect size }=0.88 \\
\text { SOT }(\mathrm{n}=22) \\
\text { Pretreatment mean }=48 \\
(95 \% \mathrm{CI}=39.9,56.1) \\
\text { Posttreatment mean }=71 \\
(95 \% \mathrm{CI}=65.4,76.5) \\
\text { Effect size }=1.41\end{array}$ & $\begin{array}{l}\text { DHI }(\mathrm{n}=4) \\
\text { Pretreatment mean }=56.5 \\
(95 \% \mathrm{CI}=44.2,68.7) \\
\text { Posttreatment mean }=32 \\
(95 \% \mathrm{CI}=8.8,55.2) \\
\text { Effect size }=1.31 \\
\text { BESS }(\mathrm{n}=4) \\
\text { Pretreatment mean }=31.5 \\
(95 \% \mathrm{CI}=29.1,33.9) \\
\text { Posttreatment mean }-16.5 \\
(95 \% \mathrm{CI}=10.5,22.9) \\
\text { Effect size }=3.09\end{array}$ & $\begin{array}{l}\text { DHI }(n=1) \\
\text { Pretreatment }=18 \\
\text { Posttreatment }=0 \\
\text { ABC }(n=1) \\
\text { Pretreatment }=75.5 \\
\text { Posttreatment }=85 \\
\text { SOT }(n=1) \\
\text { Pretreatment }=60 \\
\text { Posttreatment }=84\end{array}$ \\
\hline Evidence quality score & $20 / 22$ & $16.5 / 22$ & $8 / 10$ \\
\hline Support for the answer & Yes & Yes & Yes \\
\hline
\end{tabular}

Abbreviations: $\mathrm{ABC}=$ Activities-Specific Balance Confidence; DHI = Dizziness Handicap Inventory; SOT = Sensory Organization Test; TBI = traumatic brain injury.

\section{Implications for Practice, Education, and Future Research}

Reported and observed dizziness and imbalance following concussion can be predictors of a prolonged recovery from concussion and may not always resolve spontaneously. Preliminary research on vestibular rehabilitation to treat dizziness and imbalance shows significant improvement in most, but not all patients. Vestibular rehabilitation should be considered as an option for patients with prolonged dizziness and imbalance following concussion. Patients should be evaluated on a case-by-case basis to determine if vestibular rehabilitation is appropriate for them. Furthermore, athletic trainers should possess the evaluation tools necessary to determine if a concussed individual is a good candidate for 
vestibular rehabilitation. These tools include standard postural assessments, such as the BESS, as well as the Vestibular/Ocular Motor Screening (VOMS) and the Dix-Hallpike maneuver to assess for BPPV. Additionally, patient-reported outcomes, such as the DHI, ABC, and the Convergence Insufficiency Symptom Survey (CISS), can be helpful in determining which treatment route to take. Schneider et al. ${ }^{11}$ also reported that vestibular rehabilitation in combination with cervical rehabilitation can be beneficial for patients who have postconcussion dizziness and imbalance of cervicogenic origin, showing the potential benefits of multimodal therapy.

Once a clinician can determine the specific functional deficiencies of a patient, exercises familiar to athletic trainers can be implemented. Many of the exercises involved in the examined studies are commonly used by athletic trainers to improve balance and proprioception for a multitude of lower extremity injuries. There are five main categories of vestibular exercises: (a) eye-head coordination, (b) sitting balance, (c) standing static balance, (d) standing dynamic balance, and (e) ambulation. ${ }^{3}$ For each of these exercise types, there are 10 modifiers to progress and regress each exercise in difficulty: (a) the posture with which the exercise is performed, (b) the support surface, (c) the size of the base of support, (d) the trunk position, (e) arm position, (f) the direction of head movements, (g) the directions of whole-body movements, (h) the visual input, (i) the presence of absence of a dual cognitive task, and (j) any other special circumstances. ${ }^{3}$ Table 3 presents a summary of examples for each modifier. ${ }^{3}$ Modifications can be molded to fit specific functional deficits of each patient. Clinicians should incorporate both clinician- and patient-reported outcomes measures to effectively assess progress.

Each outcome measure of interest showed substantial improvement as a whole following vestibular rehabilitation. While not every patient made improvement and there was some variability in the magnitude of improvement between patients, the overall trend was that of decreased imbalance and self-reported dizziness. For the Alsalaheen et al. ${ }^{10}$ cohort, dizziness severity decreased from $21(\mathrm{SD}=22 ; 95 \% \mathrm{CI}=15.5,26.5)$ to $12(\mathrm{SD}=18 ; 95 \%$ $\mathrm{CI}=7.5,16.5$; $\mathrm{ES}=0.448)$; ABC increased from $64(\mathrm{SD}=27$; $95 \% \mathrm{CI}=57.45,70.55)$ to $84(\mathrm{SD}=17 ; 95 \% \mathrm{CI}=79.88,88.12$; $\mathrm{ES}=0.89)$; DHI decreased from $49(\mathrm{SD}=21 ; 95 \% \mathrm{CI}=43.94$, $54.06)$ to $30(\mathrm{SD}=22 ; 95 \% \mathrm{CI}=24.7,35.3 ; \mathrm{ES}=0.88)$; and $\mathrm{SOT}$ composite score increased from $48(\mathrm{SD}=19 ; 95 \% \mathrm{CI}=39.9,56.1)$ to $71(\mathrm{SD}=13 ; 95 \% \mathrm{CI}=65.46,76.54 ; \mathrm{ES}=1.41) .{ }^{4}$ For the Kleffelgaard et al. ${ }^{1}$ cohort, DHI decreased from 56.5 (SD = $12.26 ; 95 \% \mathrm{CI}=44.24,68.76)$ to $32(\mathrm{SD}=23.21 ; 95 \% \mathrm{CI}=$ 8.97, 55.21; $\mathrm{ES}=1.32$ ) and BESS tests decreased from 31.5 $(\mathrm{SD}=2.38 ; 95 \% \mathrm{CI}=29.12,33.88)$ to $16.5(\mathrm{SD}=6.45 ; 95 \% \mathrm{CI}$ $=10.5,22.95 ; \mathrm{ES}=3.09) .{ }^{1}$ Gottshall and Sessom' $\mathrm{s}^{9}$ participant had improvements of 9.5, 18, and 24 in the ABC, DHI, and SOT composite scores, respectively. Table 4 averages outcome measures pre- and posttreatment across all studies.

Although there was some variation between studies with regard to their definition of prolonged recovery, the vast majority were symptomatic for at least 21 days before an initial evaluation. For the Alsalaheen et al. ${ }^{10}$ cohort, the range of time from injury to initial evaluation was wide (6-2,566 days), however, only $7 \%$ of these individuals had an initial evaluation within 3 weeks of injury. This study indicates that, regardless of the magnitude of prolonged recovery, initiation of vestibular rehabilitation seems to be beneficial for resolving symptoms, provided the patient is a good candidate. After the onset of intervention, an individual who was experiencing symptoms for 2 months received the same benefits of an individual who was experiencing symptoms for 6 months.

Concussion recovery continues to be an area of emerging research. Due to this focus, this topic should be revisited in 2 years, or as additional research is published. While the findings were consistent across studies, the level of research was weak. Future research needs to determine appropriate duration and intensity

Table 3 Summary of Vestibular Therapeutic Exercise Modifiers ${ }^{3}$

\begin{tabular}{ll}
\hline Modifier & Options \\
\hline Posture & Sitting, standing, walking, n/a \\
Surface & Level, foam, uneven, obstacle, stairs, ramps, n/a \\
Base of support & Feet-apart, feet together, semi-tandem stance, tandem stance \\
Trunk position & Upright, leaning, rotated, n/a \\
Arm position & Weight bearing, close to body, away from body, reaching, carrying, picking up objects, juggling, n/a \\
Head movement direction & Still, yaw, pitch, roll, n/a \\
Whole-body movement direction & Anterior-posterior, medial-lateral, multi-directional \\
Visual input & Eyes closed, eyes open, complex patterns, n/a \\
Cognitive dual task & Yes, no \\
Special circumstances & Specific parameters for exercises (e.g., visual targets near or far) \\
\hline
\end{tabular}

Table 4 Combined Mean Scores and Differences in Outcome Measures

\begin{tabular}{lcccc}
\hline Outcome & $\mathbf{n}$ & Pre & Post & Mean Difference \\
\hline Dizziness severity & 64 & 21 & 12 & 9 \\
ABC & 69 & 69.75 & 84.5 & 9.5 \\
DHI & 74 & 41.17 & 20.67 & 20.5 \\
SOT & 23 & 54 & 77.5 & 23.5 \\
BESS & 4 & 31.5 & 16.5 & 15 \\
\hline
\end{tabular}

Abbreviations: $\mathrm{ABC}=$ Activities-Specific Balance Confidence; BESS = Balance Error Scoring System; DHI = Dizziness Handicap Inventory; SOT = Sensory Organization Test. 
guidelines for vestibular therapeutic exercises in a prospective cohort design. In addition, control groups should be included so that the therapeutic effect of time can be taken into account.

\section{CAT Kill Date: May 2021}

CATS have limited life and should be revisited approximately 2 years after publication (see https://doi.org/10.1123/ijatt.2018-0093).

\section{References}

1. Kleffelgaard I, Lundgaard Soberg H, Bruusgaard KA, Tamber AL, Langhammer B. Vestibular rehabilitation after traumatic brain injury: case series. Phys Ther. 2006;96(6):839-849. doi:10.2522/ ptj.20150095

2. Peterson MD. A case-oriented approach exploring the relationship between visual and vestibular disturbances and problems of higherlevel mobility in persons with traumatic brain injury. J Head Trauma Rehabil. 2010;25(3):193-205. PubMed ID: 20473093 doi:10.1097/ HTR.0b013e3181dc82fa

3. Alsalaheen BA, Whitney SL, Mucha A, Morris LO, Furman JM, Sparto PJ. Exercise prescription patterns in patients treated with vestibular rehabilitation after concussion. Physiother Res Int. 2013; 18(2):100-108. PubMed ID: 22786783 doi:10.1002/pri.1532

4. Valovich McLeod TC, Hale TD. Vestibular and balance issues following sport-related concussion. Brain Inj. 2015;29(2):175-184. PubMed ID: 25291297 doi:10.3109/02699052.2014.965206
5. Lau B, Lovell MR, Collins MW, Pardini J. Neurocognitive and symptom predictors of recovery in high school athletes. Clin J Sport Med. 2009;19(3):216-221. PubMed ID: 19423974 doi:10.1097/JSM. 0b013e31819d6edb

6. Chamelian L, Feinstein A. Outcome after mild to moderate traumatic brain injury: the role of dizziness. Arch Phys Med Rehabil. 2004; 85(10):1662-1666. PubMed ID: 15468028 doi:10.1016/j.apmr.2004. 02.012

7. Mucha A, Collins MW, Elbin RJ, et al. A brief Vestibular/Ocular Motor Screening (VOMS) assessment to evaluate concussions. Am J Sports Med. 2014;42(10):2479-2486. PubMed ID: 25106780 doi:10. $1177 / 0363546514543775$

8. Iverson GL, Gardner AJ, Terry DP, et al. Predictors of clinical recovery from concussion: a systematic review. $\mathrm{Br} J$ Sports Med. 2017;51(12):941-948. PubMed ID: 28566342 doi:10.1136/bjsports2017-097729

9. Gottshall KR, Sessoms PH. Improvements in dizziness and imbalance results from using a multi-disciplinary and multi-sensory approach to vestibular physical therapy - a case study. Front Syst Neurosci. 2015;9(106):1-7. doi:10.3389/fnsys.2015.00106

10. Alsalaheen BA, Mucha A, Morris LO, et al. Vestibular rehabilitation for dizziness and balance disorders after concussion. J Neurol Phys Ther. 2010;34(2):87-93. PubMed ID: 20588094 doi:10.1097/NPT. 0b013e3181dde568

11. Schneider KJ, Meeuwisse WH, Nettel-Aguirre A, et al. Cervicovestibular rehabilitation in sport-related concussion: a randomised controlled trial. Br J Sports Med. 2014;48(17):1294-1298. PubMed ID: 24855132 doi:10.1136/bjsports-2013-093267 